\title{
Variability in Yield and Fiber Technological Properties of Cotton (Gossypium hirsutum L.)
}

\author{
Emine KARADEMIR ${ }^{1}$, Cetin KARADEMIR ${ }^{1}$, Remzi EKINCI' ${ }^{1}$, Oktay GENCER² \\ ${ }^{1}$ Ministry of Agriculture and Rural Affairs, General Directorate of Agricultural Research, Southeastern Anatolia \\ Agricultural Research Institute, 21110 Diyarbakır,Turkey; emine_karademir@hotmail.com \\ ${ }^{2}$ University of Cukurova, Cotton Research and Application Center, Adana, Turkey
}

\begin{abstract}
The aim of this study was to determine the variability in yield and fiber technological properties in advanced cotton lines developed through cotton breeding program of the Southeastern Anatolia Agricultural Research Institute (SAARI). The experiment was conducted in the SAARI's experimental field according to Augmented Design (AD) with six replications. In the study, 66 advanced cotton breeding lines and 3 control varieties ('Stoneville 468', 'GW-Teks', and 'Fantom') were used as plant materials. Variation levels of 69 genotypes in yield and fiber technological properties were measured. Minimum and maximum values were $3337.60-6644.20 \mathrm{~kg} \mathrm{ha}^{-1}$ for seed cotton yield, $1277.10-2659.20 \mathrm{~kg} \mathrm{ha}^{-1}$ for fiber yield, and 34.28-41.70\% for ginning percentage. Statistical analysis indicated that great majority of the plants (47.82\%) had values between $4990.90-5817.55 \mathrm{~kg} \mathrm{ha}^{-1}$ for seed cotton yield and $53.62 \%$ had values between 1968.15 $2313.68 \mathrm{~kg} \mathrm{ha}^{-1}$ for fiber yield. It was determined that ginning percentage was more than $39.85 \%$ for the $10.14 \%$, fiber length was more than $29.76 \mathrm{~mm}$ for the $18.84 \%$, fiber strength was more than $31.78 \mathrm{~g} \mathrm{tex}^{-1}$ for the $8.7 \%$, and fiber uniformity was more than $86.55 \%$ for the $13.05 \%$ of the materials. It was also determined that $1.45 \%$ of the material was very thin and $13.04 \%$ of the material was above $6.59 \%$ for fiber elongation and for short fiber index of $46.38 \%$ of the material ranged from 6.90 to 7.63 .
\end{abstract}

Keywords: cotton, fiber technological properties, variability, yield

\section{Introduction}

Cotton is the most important fiber crop used in the textile industry in the world and making up more than half of textile fiber consumption worldwide. Growth and competitiveness of the cotton industry are dependent upon continuing improvements in yield, fiber quality and pest resistance (Ulloa et al., 2009). Breeding for high cotton lint yield is still the primary goal of any breeding program, but improving fiber quality has become increasingly important (Meredith et al., 1991; Ulloa and Meredith, 2000). Thus, most of the cotton improvement programs are focused on development of yield and fiber quality. Cotton is highly responsive to changes in temperature, humidity, and soil moisture, which may affect its yield, yield components, and fiber properties (Killi et al., 2005). Hake et al. (1996) revealed that the effects of location and the influence of the season are more significant than variety differences for yield. Also, environmental conditions play an important role in variability of cotton fiber quality. It has been shown that cotton fiber quality changes with boll location within the plant and planting dates (Davidonis et al., 2004) and fiber quality is affected by harvesting and ginning methods (Sassenrath, 2005). Kothari et al. (2007) revealed that fiber quality varies drastically depending on where the fibers are picked from within the plant and quality of the fibers declines from bottom of the plant to the top. Development of effective breeding programs depends on the existence of genetic variability for various economic characteristics (Sakthi et al., 2007). The primary objectives of this study were to determine the variability in yield and fiber technological properties for advanced cotton breeding lines developed from cotton breeding program and their comparisons to the most commonly used control varieties.

\section{Materials and methods}

The study was conducted in the experimental field of Southeastern Anatolia Agricultural Research Institute, during 2009 cotton growing season in Turkey. The experimental area is located at $37^{\circ} 94^{\prime} \mathrm{N}$ and $40^{\circ} 25^{\prime} \mathrm{E}$ longitude, at the elevation of above $609 \mathrm{~m}$ of the sea level. The soils of the experimental area were zonal soils which are generally red-brown and included in the big soil group having a clayish nature, flat or about-to-be flat, having very small erosion and deep or medium deep. The soil is low in organic matter and phosphorus, has adequate potassium, calcium, and high clay content (49-67\%) in the $0-150 \mathrm{~cm}$ profile. The average annual temperature is $15.8^{\circ} \mathrm{C}$, total rainfall is $491 \mathrm{~mm}$ and the average relative humidity is about $29.9 \%$. The average maximum temperature can reach $38.3^{\circ} \mathrm{C}$ in July and average rainfall can reach $70.5 \mathrm{~mm}$ in April. 
136

The experiment was laid out according to Augmented Design (AD) with six replications. The materials used in the study were developed from cotton breeding program of the Southeastern Anatolia Agricultural Research Institute. In the study, 69 genotypes ( 66 advanced cotton breeding lines and 3 control varieties ('Stoneville 468', 'GW-Teks', and 'Fantom') were used as plant materials. Each plot consisted of two rows of $12 \mathrm{~m}$ length, between and within row spacing were $0.70 \mathrm{~m}$ and $0.20 \mathrm{~m}$, respectively. Seeds were planted on $8^{\text {th }}$ May 2009, before sowing $2000 \mathrm{cc} \mathrm{ha}^{-1}$ doses of herbicide (total herbicide, Trifluralin) were applied for weed control, plants were grown under recommended cultural practices for commercial production. Drip irrigation was applied during the growing season. Plots were harvested twice by hand and the harvests from the two rows of the plot were weighed and calculated for seed cotton yield and fiber yield. The first harvest was done on $23^{\text {rd }}$ October and the second harvest was done on $11^{\text {th }}$ November 2009. After the harvest, seed cotton samples were ginned on a mini-laboratory roller-gin for lint percentage and fiber quality. Fiber samples were analyzed for fiber quality properties by High Volume Instrument (HVI Spectrum).

The data were analyzed using JMP 5.0.1 and TOTEMSTAT statistical programs. Frequency distribution related to the yield and fiber technological properties of the material were created in the EXCEL program.

\section{Results and discussion}

The analysis of variance of the investigated characteristics and the obtained findings from the experiment are presented in Tab. 1 and frequency distribution related to yield and fiber technological properties are presented in figures.

The CV (variation coefficient) ranged from $1.11 \%$ for fiber uniformity to $15.26 \%$ for fiber yield. Fiber uniformity has the lowest $\mathrm{CV}$ among the other fiber technological properties and yields (Tab. 1). The variation in fiber quality in this study is generally small with a CV $<6.00 \%$ for all properties which supports the results of other studies where CVs for fiber quality were much lower than those of lint yields (Ge et al., 2008)
The results of the analysis of variance indicated that seed cotton yield ranged from 3337.6 to $6644.2 \mathrm{~kg} \mathrm{ha}^{-1}$ in the population. The average seed cotton yield was 5309.4 $\mathrm{kg} \mathrm{ha}^{-1}$ (Tab. 1). It was determined that $47.82 \%$ of the material's seed cotton yield was between $4990.90-5817.55 \mathrm{~kg}$ $\mathrm{ha}^{-1}$ (33 cotton breeding lines) and $24.64 \%$ of the material (17 cotton breeding lines) was higher than $5817.55 \mathrm{~kg}$ ha $^{-1}$ (Fig. 1). Whereas 'Stoneville 468', 'Fantom' and 'GWTeks' control varieties had values of $5027.77,4599.70$, and $4441.96 \mathrm{~kg} \mathrm{ha}^{-1}$, respectively. These findings showed that seed cotton yield of the most of the new cotton genotypes (48 cotton breeding lines) had higher values than the best control variety ('Stoneville 468').

Fiber yield in all materials ranged between 1277.10$2659.20 \mathrm{~kg} \mathrm{ha}^{-1}$. The average fiber yield was $2017.60 \mathrm{~kg}$ $\mathrm{ha}^{-1}$. It was shown that $53.62 \%$ of the material's fiber yield was between 1968.15-2313.68 $\mathrm{kg} \mathrm{ha}^{-1}$ (37 cotton breeding lines) and $10.14 \%$ of the material's (only 7 cotton breeding lines) fiber yield was higher than $2313.68 \mathrm{~kg} \mathrm{ha}^{-1}$ (2313.68-2659.20 kg ha' ${ }^{-1}$ Fig. 2). In the study, fiber yield obtained from control varieties 'Stoneville 468,' 'Fantom' and 'GW-Teks' were 2057.84, 1793.08, and $1765.85 \mathrm{~kg}$ $\mathrm{ha}^{-1}$, respectively. The data in this study showed that some progress has been made for cotton yield and fiber yield. Similar results were also reported by Zhang et al. (2007). However, Meredith et al. (1997), reported that breeding progress for increased yield has greatly decreased in recent times in the United States and the world.

Ginning percentage of the material being tested indicated that the values ranged from 34.28 to $41.70 \%$ and the average of ginning percentage was $37.94 \%$. It was determined that $42.03 \%$ of the material's ginning percentage values varied between $36.13-37.99 \%$ ( 29 cotton breeding lines), $39.13 \%$ of the material's ginning percentage values varied between $37.99-39.85 \%$. In the study, $10.14 \%$ of the material's (only 7 cotton breeding lines) ginning percentage values were higher than $39.85 \%$ (39.85 to $41.70 \%$ ) as shown in Fig 3. A large amount of variation for this trait was detected between 34.27 to $41.70 \%$. Similar results were also reported by (Khan et al., 2009). Ulloa and Meredith (2000) detected three QTLs for lint percentage, explaining from 5 to $20 \%$ of the variation of this trait.

Tab. 1. Analysis of variance of the investigated traits

\begin{tabular}{ccccccc}
\hline Investigated traits & Min. & Max. & Average & Variance & Stand. deviation & VariationCoefficient \% \\
\hline Seed cotton yield $\left(\mathrm{kg} \mathrm{ha}^{-1}\right)$ & 3337.60 & 6644.20 & 5309.40 & 4571.50 & 67.61 & 14.22 \\
\hline Fiber yield $\left(\mathrm{kg} \mathrm{ha}^{-1}\right)$ & 1277.10 & 2659.20 & 2017.60 & 750.07 & 27.38 & 15.26 \\
Ginning percentage (\%) & 34.28 & 41.70 & 37.94 & 2.28 & 1.51 & 2.37 \\
\hline Fiber length $(\mathrm{mm})$ & 25.19 & 31.29 & 28.28 & 2.29 & 1.51 & 2.27 \\
Fiber fineness $\left(\right.$ micronaire $^{-19}$ & 3.63 & 5.37 & 4.69 & 0.12 & 0.34 & 5.01 \\
\hline Fiber strength $\left(\mathrm{g} \mathrm{tex}^{-1}\right)$ & 24.71 & 34.14 & 28.79 & 4.95 & 2.22 & 5.54 \\
\hline Fiber uniformity $(\%)$ & 82.28 & 87.98 & 85.17 & 1.49 & 1.22 & 1.11 \\
\hline Fiber elongation (\%) & 5.07 & 7.10 & 6.06 & 0.19 & 0.44 & 5.90 \\
\hline Short fiber index $(\%)$ & 6.18 & 9.08 & 7.53 & 0.33 & 0.57 & 3.34 \\
\hline
\end{tabular}




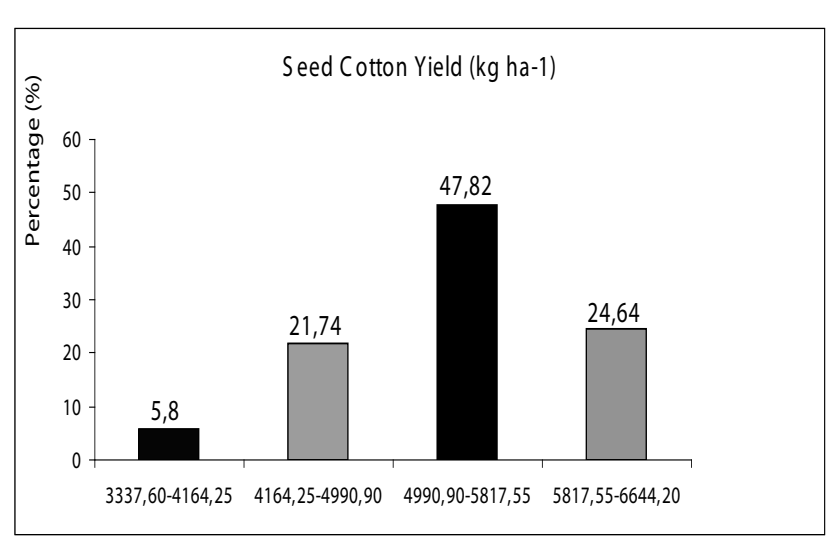

Fig. 1. Frequency distribution for seed cotton yield $\left(\mathrm{kg} \mathrm{ha}^{-1}\right)$

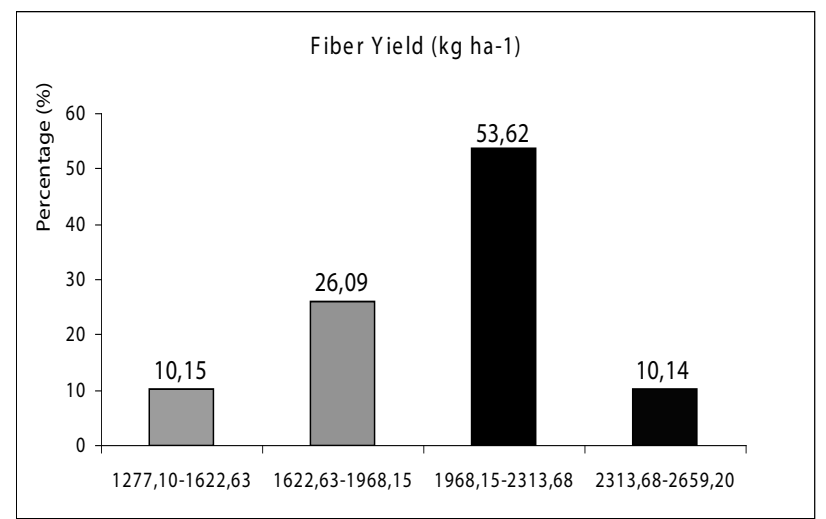

Fig. 2. Frequency distribution for fiber yield $\left(\mathrm{kg} \mathrm{ha}^{-1}\right)$

In all samples, fiber length was between 25.19 to 31.29 $\mathrm{mm}$ and the average fiber length was $28.28 \mathrm{~mm}$. Fiber length of about one-third of the material (31.88\%) fell within the range of 26.71 to $28.24 \mathrm{~mm}$ (22 cotton breeding lines). It was determined that $18.84 \%$ of the material's (13 cotton breeding lines) was higher than $29.76 \mathrm{~mm}$ ( 29.76 to $31.29 \mathrm{~mm}$ ) as shown in Fig 4. Fiber lengths of 'GW-Teks', 'Fantom', and 'Stoneville 468' control were recorded as 30.00, 29.90, and $28.94 \mathrm{~mm}$, respectively. In the study, 9 cotton breeding lines had higher values than the control variety 'GW-Teks' for this trait. Similar results were reported by Elms et al. (2001) who observed average fiber length between $24-30 \mathrm{~mm}$ and the CVs for fiber length ranged from 2.3 to $4.2 \%$ in their studies. Fiber length is primarily determined by the variety, but is also influenced by temperature, water, nutrient stresses, and planting date (Elms et al., 2001; Davidonis et al., 2004). Contradictory results can result from the cultivars having different genetic backgrounds and from changes in environmental conditions.

Fiber fineness of all samples variation level was recorded between 3.63-5.37 mic., and the average fiber fineness was 4.69 mic. (Tab.1) Frequency distribution of fiber fineness depicted that $37.68 \%$ of the material ( 26 cotton breeding lines) was between 4.50-4.93 mic., and 21 cotton breeding lines (30.43\% of the material) was between $4.06-4.50$ mic., and only 1 genotype was below 4.06 mic. (1.45\% of the material). Similar results were also reported by Kara-

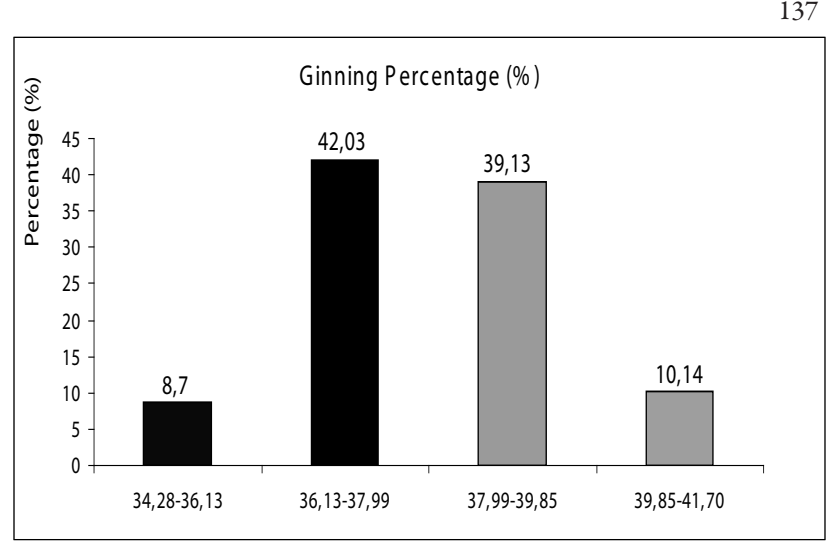

Fig. 3. Frequency distribution for ginning percentage (\%)

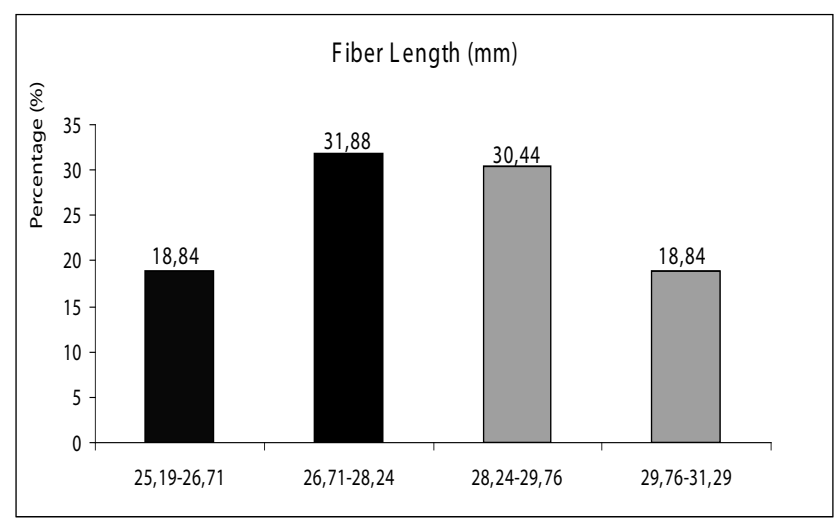

Fig 4. Frequency distribution for fiber length $(\mathrm{mm})$

demir et al. (2001). Asif et al. (2008) revealed higher coefficient of variability for fiber fineness and suggested that this character is highly influenced by non-genetic biotic and abiotic factors. Elms et al. (2001) observed an average fiber micronaire between 4.5-5.1 and they reported that lower micronaire values were associated with immature fibers.

In the experiment, significant variations observed for fiber strength varied from 24.71 to $34.14 \mathrm{~g} \mathrm{tex}^{-1}$ and mean value for this trait was $28.79 \mathrm{~g} \mathrm{tex}^{-1}$. The CVs for fiber strength were $4.95 \%$ as seen in Tab. 1. It was observed that $8.70 \%$ of the material's fiber strength were between $31.78-34.14 \mathrm{~g} \mathrm{tex}^{-1}$ and was situated as the strongest group ( 6 cotton breeding lines), $30.43 \%$ of the material were between 29.42-31.78 $\mathrm{g} \mathrm{tex}^{-1}$ and situated as strong group ( 21 cotton breeding lines), and the remaining was lower than $29.42 \mathrm{~g} \mathrm{tex}^{-1}$. Fiber strength of control varieties used in the study was recorded as 33.20, 30.33, and $30.10 \mathrm{~g} \mathrm{tex}^{-1}$ for 'GW-Teks', 'Fantom', and 'Stoneville 468', respectively. Royo et al. (2003) revealed acceptable variability for fiber strength between 19.5-35.9 $\mathrm{g} \mathrm{tex}^{-1}$.

The fiber elongation values of genotypes being tested indicated that the values were ranged from 5.07 to $7.10 \%$ (Fig 7). Average fiber elongation was $6.06 \%$. It was observed that $13.04 \%$ of the material's fiber elongation values were above 6.59 (6.59-7.10\%). However higher proportion of the material (42.03\%) was between 5.58-6.08\%. Similar results were also reported by Ali et al. (2010). 
138

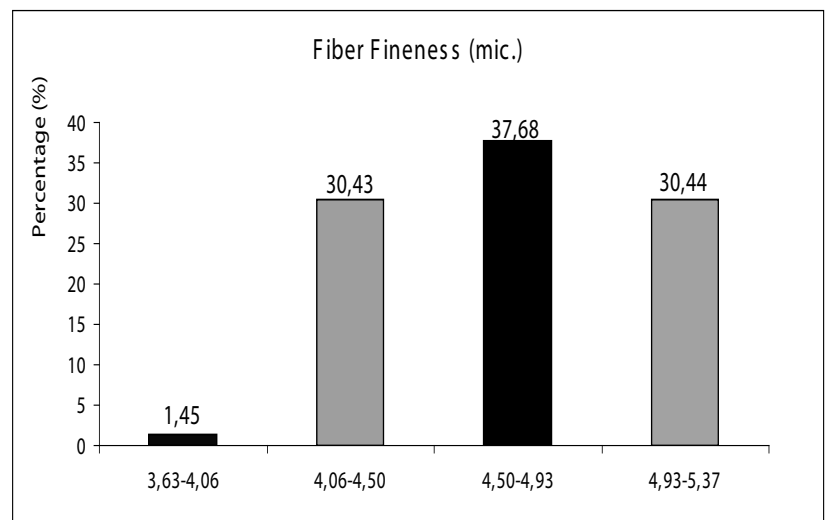

Fig. 5. Frequency distribution for fiber fineness (mic)

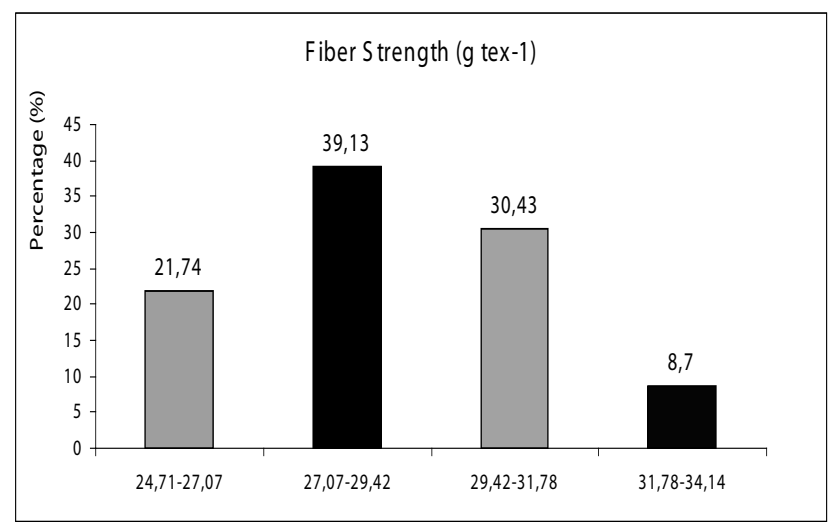

Fig. 6. Frequency distribution for fiber strength $\left(\mathrm{g} \mathrm{tex}^{-1}\right)$

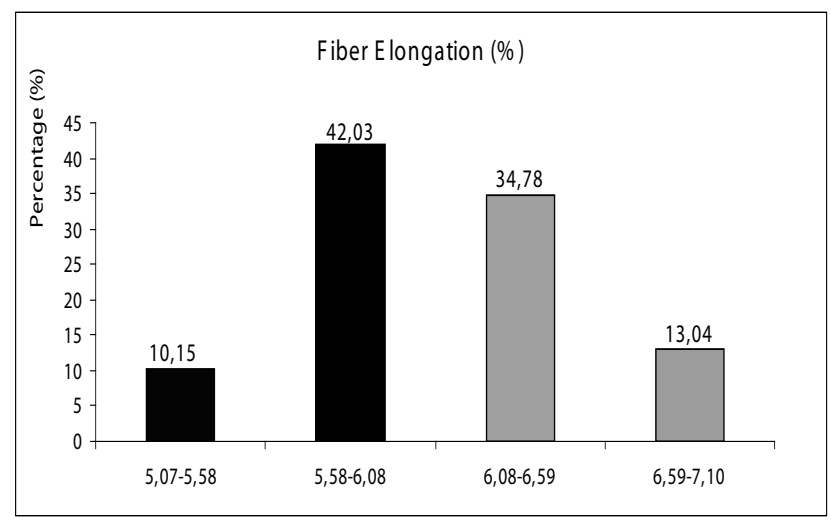

Fig. 7. Frequency distribution for fiber elongation (\%)

Minimum and maximum values for fiber uniformity ranged between $82.28-87.98 \%$ and average fiber uniformity was $85.17 \%$. Highly great proportion of the material (42.03\%) for fiber uniformity ranged from 85.13 to $86.55 \%$ (Fig. 8). The lowest fiber uniformity value of $82.27 \%$ obtained from the study meets the textile industry requirements.

Short fiber index ranged between 6.18 to $9.08 \%$, with an average of $7.53 \%$. Frequency distribution for short fiber index showed that $46.38 \%$ of the material was between 6.90 and 7.63. The results of this study show that short fiber index values of all materials were at acceptable level

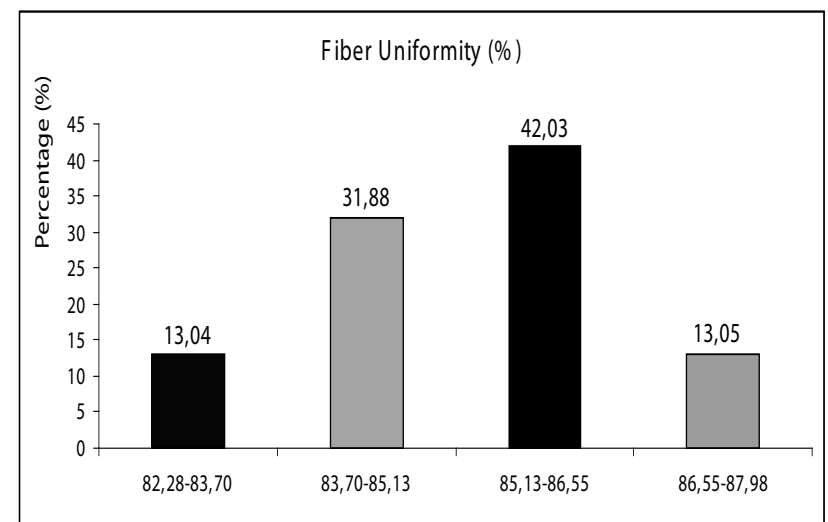

Fig. 8. Frequency distribution for fiber uniformity (\%)

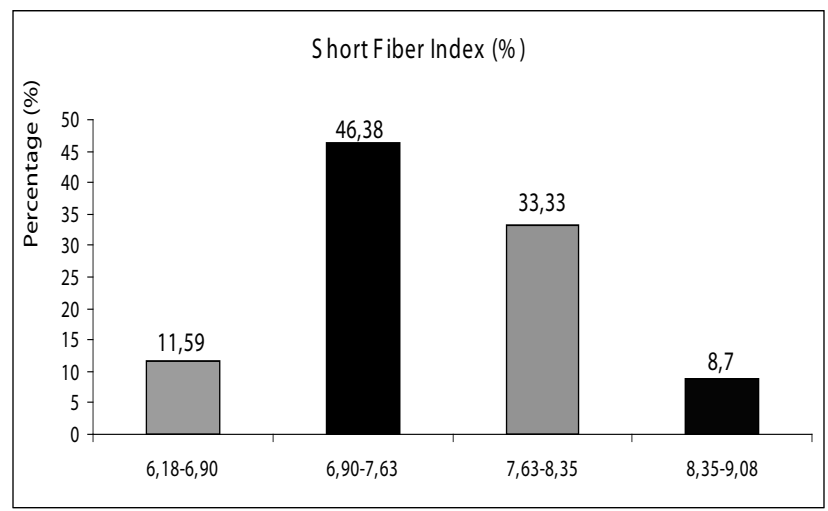

Fig. 9. Frequency distribution for short fiber index (\%)

for the textile industry. Excessive short fiber content is detrimental because it increases textile manufacturing waste, reduces yarn strength, and increases the difficulty of spinning (Hake et al., 1996).

\section{Conclusions}

In conclusion, in this study very large variations were observed for seed cotton yield and fiber yield. The variation in fiber quality properties is generally smaller than seed cotton yield and fiber yield. Fiber uniformity has the lowest variation among the other fiber technological properties and yields. In this study, 69 genotypes evaluated and variation levels for yield and fiber technological properties were measured. The results of this study contain information could assist cotton breeders and textile sectors.

\section{Acknowledgements}

We would like to thank the General Directorate of Agricultural Research of the Ministry of Agriculture and Rural Affairs (Turkey) for supporting this research.

\section{References}

Ali MA, Khan IA, Nawab NN (2010). Estimation of Genetic Divergence and Linkage for Fiber Quality Traits in Upland Cotton. J Agric Res 47:229-236. 
Asif M, Mirza JI, Zafar Y (2008). Genetic Analysis for fiber quality traits of some cotton genotypes. Pak J Bot 40:12091215.

Davidonis GH, Johnson AS, Landivar JA, Fernandez CJ (2004). Cotton fiber quality is related to boll location and planting date. Agron J 96:42-47.

Elms M, Green CJ, Johnson PN (2001). Variability of Cotton Yield and Quality. Commun Soil Sci Plant Anal 32:351368.

Ge Y, Thomasson JA, Sui R, Morgan CL, Searcy SW, Parnell CB (2008). Spatial variation of fiber quality and associated loan rate in a dryland cotton field. Precision Agriculture 9:181 194.

Hake KD, Bassett DM, Kerby TA, Mayfield WD (1996). Procuding Quality Cotton. Div. Agric. Nat. Res. Publ. 3352 University of California, Oakland, CA, USA, p. 134-149.

Karademir E, Başbağ S, Karademir Ç (2001). An Investigation for technological properties of some cotton lines and varieties in Diyarbakır Conditions. 4. Field Crop Congress of Turkey, p. 325-330.

Khan NU, Hassan G, Kumbhar MB, Marwat KB, Khan MA, Parveen A, Aiman U, Saeed M (2009). Combining Ability Analysis to Identify Suitable Parents for Heterosis in Seed Cotton Yield, its Components and Lint \% in Upland Cotton. Industrial Crops and Products 29:108-115.

Kothari N, Abidi N, Hequet E, Wilkins T (2007). Fiber Quality Variability Within a Plant. http://wcrc.confex.com/data/ abstract/wcrc/2007/Paper_1800_abstract_2152_0.pdf.

Killi F, Efe L, Mustafayev S (2005). Genetic and Environmental Variability in Yield, Yield Components and Lint Quality Traits of Cotton. Internat J Agricul Biol 6:1007-1010.
Royo OM, Poisson J, Montenegro A (2003a). Morphologica Traits Characterisation and Some Yield and Fiber Quality Components Evaluation of the Argentinian Cotton Genetic Resources Collection http://www.inta.gov.ar/saenzpe/ info/documentos/algodon/cara.pdf.

Meredith WR Jr, Culp TW, Robert KO, Ruppenicker GF, Anthony WS, Williford JR (1991). Determining future cotton variety fiber quality objectives. Tex Res J 61:720723.

Meredith WR Jr, Heitholt JJ, Petigrew WT, Rayburn ST (1997). Comparison of Obsolete and Modern Cotton Cultivars at Two Nitrogen Levels. Crop Sci 37:1453-1457

Sassenrath GF (2005). Impact of Harvesting and Ginning on Fiber Properties. http://www.cotton.org/beltwide/ proceedings/2005-2010/data/conferences/2005/ pdfs/2660.pdf

Sakhti AR, Kumar M, Ravikesavan R (2007). Variability and Association Analysis Using Morphological and Quality Traits in Cotton (Gossypium hirsutum). J Cotton Res Dev 21:148-152

Ulloa M, Meredith WR (2000). Genetic Linkage Map and QTL Analysis of Agronomic and Fiber Quality Traits in an Intraspecific Population. The J Cotton Sci 4:161-170.

Ulloa M, Percy R, Hutmacher RB, Zhang J (2009). The Future of Cotton Breeding in the Western United States. The J Cotton Sci 13:246-255.

Zhang J, Cantrell RG, Waddell C, Hughs E (2007). New Acala Germplasm Lines With High Yield Potential and Fiber Quality. Beltwide Cotton Conferences, New Orleans, Louisiana, p. 205-216. 